\title{
Parental Occupation in Pre and Postnatal among Autism Spectrum Disorder
}

\author{
Smily Jesupriya Victor Paulraj ${ }^{\star}$, Siti Nur Azalia Mohamad Salleh¹, Jayachandran Vetrayan ${ }^{1}$
}

${ }^{1}$ Universiti Teknologi MARA (UiTM), Faculty of Health Science, Puncak Alam,42300, Malaysia

\begin{abstract}
This study aimed to examine the parental occupation in pre and post-natal among Autism Spectrum Disorder (ASD) and to identify the desired factors to work. The 124 samples ages between 26 to 52 years old including 59 males and 65 females from 5 difference rehabilitation centres were recruited. A self-rated parental occupation questionnaire was used to measure. Finding shows the parent who works in the high professionals and technicals has a high risk of having ASD. The factors which contribute to the desired parents to work in that field are earning more money, knowledge development and satisfying basic needs.

(c) 2016. The Authors. Published for AMER ABRA by e-International Publishing House, Ltd., UK. This is an open access article under the CC BYNC-ND license (http://creative commons.org/licenses/by-nc-nd/3.0/).

Peer-review under responsibility of AMER (Association of Malaysian Environment-Behaviour Researchers), ABRA (Association of Behavioural Researchers on Asians) and $c E-B s$ (Centre for Environment-Behaviour Studies), Faculty of Architecture, Planning \& Surveying, Universiti Teknologi MARA, Malaysia.
\end{abstract}

Keywords: Parental occupation; Autism spectrum disorder; Prenatal; Post-natal

\section{Introduction}

Autism Spectrum Disorder (ASD) is a complex neurodevelopment disorder that has diagnosed for many years (Griffin and Westbury, 2011). The prevalence of ASD is 1 in 68 children in the United States (ADDM Surveillance Year 2010 Principal Investigators, 2014). In Malaysia; the prevalence of ASD according to a local survey is around 1 out of 625 children (Azizan, 2008). For 2016, there is no official statistical report on a total number of children with ASD in Malaysia. But the statistics revealed that in 2010, the total number of ASD from age ranged $0-14$ in Malaysia was 9,164,470 (Department of Statistic Malaysia, 2010). Recent studies stated that there is cognitive, social, visual perception, imitations, and emotional deficits in children with autism (Senju 2013; Jayachandran et al., 2015; Nurul'Ain et al., 2015; Smily et al., 2015 \& 2016). Aetiology of ASD is still unknown.

\footnotetext{
* Smily Jesu Priya.V. Tel.: 601126185754

E-mail address: jesusmily@gmail.com
}

2398-4287 @ 2016. The Authors. Published for AMER ABRA by e-International Publishing House, Ltd., UK. This is an open access article under the CC BY-NC-ND license (http://creative commons.org/licenses/by-nc-nd/3.0/).

Peer-review under responsibility of AMER (Association of Malaysian Environment-Behaviour Researchers), ABRA (Association of Behavioural Researchers on Asians) and cE-Bs (Centre for Environment-Behaviour Studies), Faculty of Architecture, Planning \& Surveying, Universiti Teknologi MARA, Malaysia.

DOI: http://dx.doi.org/10.21834/e-bpj.v1i3.344 
However, many studies suggested that there are multiple risk factors which contribute to the development of autism spectrum disorder which includes genetic factor and environment factor (Guney and Iseri, 2013; Kalkbrenner, Schmidt and Penlesky, 2014). Few studies reported that parental occupation might be one of the risk factors for ASD.

\subsection{Literature review}

Baron-Cohen, Wheelwright, Stott, Bolton and Goodyer (1997) has conducted a study to identify the relationship between engineering's and children with ASD. The study investigated about $28.4 \%$ who had a father or grandfather who was engineering in a sample of 919 families that having autistic children. The percentage is two times from a group of fathers of children with ASD, who works as engineering as compared to others control groups which includes Tourette syndrome, language delay, Down's syndrome and normal development children. Therefore, it strongly linked between engineering and autism. Another study conducted in University of Cambridge United Kingdom, whereby Baron-Cohen, Bolton, Wheelwright, Scahill, Short, Mead, and Smith (1998) identify the associations between autism with two different jobs fields either technical such as engineering, physics, mathematics and humanities such as the literature of English and French. In a sample of 1293, 641 students were from Mathematics, Physics, Engineering (MPE) group and 652 students from English and French (EF) group. Based on the result six cases of autism affected in MPE group which significantly higher rather than EF group. Additionally, Wheelwright, \& Baron-Cohen (2001) also reported that there was the significant association between autism and technical skills such as engineering, maths, physics and computing.

Jarrold and Routh (1998) found that fathers of children with ASD were not only associated with engineering field but also extended in accountancy and science. As others field like accountancy and science are the example of the profession which required more on the ability in folk physics rather than folk psychology. They agreed with the possibility of others related job after analyzing the same data. However, engineering remains the highest percentage with $24.3 \%$ to be associated with autism after they compare with others professionals. According to Diament (2014) 'Parent's line of wok may increase Autism risk'. The occupations that are requiring more technical skill and less social interaction skill have greater possibilities of having children with autism. Based on the result, fathers who are jobs in engineering, finance, and health care are among the professions of getting a higher possibility of children with ASD.

The studies mentioned that children of scientists and engineers having the chances of carrying the genetic not only the intellectual talents but also have higher chances to be autism. As most of the parents who work in technical minded are potential, carry the stereotypical occupation genes that are having the characteristic of ASD. Whereby, scientists and engineers were having the higher potential of children with Autism (Baron-Cohen, 2012 and Buchen, 2011). The recent study by Dickerson, Pearson, Loveland, Rahbar, and Filipek (2014) investigated the linked between parent occupations and diagnosis of ASD. The result found that father who works in healthcare and finance were the highest possibility to have ASD children. Previous suggested in the future study to examine about parent's occupation during the prenatal and post-natal of ASD children. Besides the study proposed to examine the desire for the parents who work in high- professional area and how the factors can contribute towards the problems in communication and social deficits among autism (Dickerson, Pearson, Loveland, Rahbar, and Filipek, 2014). Early studies were absent to examine the desire for the parents who work in high- professional area and how the factors can contribute towards autistic children.

Therefore, the purpose of the study was to examine the parental occupation in prenatal (before childbirth) and postnatal (after childbirth) among Autism spectrum disorder. Furthermore, to find the factors that may contribute to a desire to work for parents with ASD. 


\section{Methodology}

\subsection{Subjects}

The total numbers of the parents with ASD were 124 (59 male and 65 female). The sample age range was between 26 to 52 years old with participation from difference races which involved Malay $(\mathrm{N}=89)$, Chinese $(\mathrm{N}=$ 24), Indian $(\mathrm{N}=8)$ and others $(\mathrm{N}=3)$. The samples were collected five rehabilitation centers in Malaysia. The inclusion criteria of the samples were i) parents with ASD and the age ranges between 20 to 60 years old, ii) children with ASD diagnosed with child psychiatry and the age ranges between 2 to 18 years old, iii) working parents, iv) parents able to read and understand the English language and v) parent who are willing to participate in this study.

\subsection{Research Questionnaire}

The self-reported Parental Occupation Questionnaire (POQ) for ASD used in this study to examine the parental occupation during pre and postnatal among ASD. The questionnaire consists of 3 sections. Part 1 was basically to generate the parent demographic data.

Part 2 was about the parent occupations during prenatal and postnatal. It classified the type of works into ten categories which include professionals, administrative and management, scientific or analytical, creative or artistic, facilitative or assistive, technical or mechanical, nature or recreational, clerical and secretarial, sales or service and operatives. People who work as engineers, computer programmer, and IT specialist were the example of jobs under technical or mechanical categorization. Meanwhile, for those individuals who work in the health professions such as doctor, dentist, therapist and educational profession such as lecturer and teacher, legal profession such as lawyer are fall under professional categorization. Others questions that included in this section are their job scope, duration of work, working hours and rest time during working hour.

Part 3 was the factors that may desire to work in the professions. It consists of 17 questions. The rating scales using Likert scale which includes 1 for strongly disagree, 2 for disagree, 3 for neither agree nor disagree, 4 for agree and 5 for strongly agree.

\subsection{Pilot study}

Researchers have performed the pilot study to establish the validity and reliability of the instrument used. A selfreported $P O Q$ was designed based on the previous literature and consultation with various professionals for face validity. The questionnaire was the pilot on a convenience sample of 15 health professionals. Questionnaires and information sheets regarding this study were coded and sent to 2 Psychiatrist, 9 Occupational Therapist, 2 Clinical psychologists and 2 Special Educator of all levels and grades.

Around 30 autistic children, parents have participated in the pilot study. The sample collected in the five rehabilitation centres that fulfilled the inclusion, and exclusion criteria were involved. Test-retest reliability conducted with a total of 30 samples. 17 statements of the factors desire parent to work were analyzed. Cronbach's Alpha used to assess the reliability of the questionnaire and the total summary score for Cronbach's Alpha were 0.888. Since the value is more than 0.7 , thus the questionnaire is acceptable.

\subsection{Data Collection Procedure}

Ethical approval obtained from Research Ethics Committee Faculty of Health Sciences, Universiti Teknologi MARA (UiTM), Malaysia. As evidence of the approval, a formal letter had been received. The letter of consent obtained from Head of Occupational Therapy Department and Faculty of Health Sciences, Universiti Teknologi MARA (UiTM). The letter of approval sent to 5 difference rehabilitation centres in Malaysia to inform and get their permission to carry out the study. The participants who agreed to take part in the study were to sign a written 
consent form. Based on the screening criteria, the data collection was carried out. The self-reported POQ used to examine the pre and post natal of the parental occupation among ASD. Therefore, the self-reported POQ distributed by a researcher to the parent of autistic children who selected as respondent. After, complete answering the questionnaire and the token of appreciation was given to the participants. Finally, all the data collected have kept confidentially and just for research purpose.

\subsection{Data Analysis}

Statistical Package for the Social Sciences version 18.0 (SSPS 18.0 for Window) used in processed and analyzed all data collected. The data analyzed according to the method of descriptive and reliability analysis. The categorical data presented in the form of frequency and percentage was used to analyze the data of the respondent's demographic data, type of occupation for a parent with ASD children, duration of working, working hours and rest period during working hours. Reliability analysis conducted by using Intraclass correlation coefficient (ICC) to determine the reliability level of the factors that may desire to work on a particular job. For reviewing of results, tables and figure are employed in this study.

\section{Results}

\subsection{Reliability statistic}

With a total of 30 samples, test -retest reliability test used to measure the 17 questions were represented for the factors that may contribute to a desire to work. Reliability analysis conducted by using Cronbach Alpha and Intraclass correlation coefficient (ICC). The result for Cronbach Alpha is 0.89 , and ICC is 0.75 . Thus, it shows a good reliability as the value is greater than 0.7 .

\subsection{Descriptive statistic on demographic data}

A descriptive statistic test was used to identify the frequency and percentage on demographic data which includes gender, age, and races among the respondents. 124 parent of Autism spectrum disorder (ASD) has participated in this study. Three respondents are under exclusion criteria as they were fully homemaker with no experience in working.

Table.1. Demographic Information of Respondent

\begin{tabular}{lllll}
\hline Variables & Categories & $\begin{array}{l}\text { Frequencies } \\
(n=124)\end{array}$ & Percent \% & Mean (SD) \\
\hline Gender & Male & 59 & 47.6 & 1.52 \\
& Female & 65 & 52.4 & $(0.50)$ \\
Age (years) & $20-29$ & 12 & 9.6 & \\
& $30-39$ & 62 & 49.8 & 38.09 \\
& $40-49$ & 46 & 37.0 & $(6.10)$ \\
& $50-59$ & 4 & 3.2 & \\
\hline
\end{tabular}




\begin{tabular}{lllll}
\hline Races & Malay & 89 & 71.8 & 1.40 \\
& Chinese & 24 & 19.4 & $(0.72)$ \\
& Indian & 8 & 6.5 & \\
& Others & 3 & 2.4 & \\
\hline
\end{tabular}

Table 1 indicates there were 59 male and 69 female of a parent of ASD, who involved in this study. Female group is greater percentage as compared to male group with $52.4 \%(n=65)$ and $47.6 \%(n=59)$ respectively. The mean for gender was 1.52 and SD was 0.50 . The age of respondent grouped into four distinct groups. They were 20 to 29 years old, 30 to 39 years old, 40 to 49 years old and 50-59 years old. The mean age among the respondents was 38.09 years old, and SD was 6.10. The highest percentage based on age group among parent of ASD was 30 to 39 years old with $49.8 \%$ ( $n=62$ ), the second highest age group among parent of ASD was 40 to 49 years old with $37.0 \%(n=46)$, the third age group among parent of ASD was 20 to 29 years old with $9.6 \%(n=12)$, and last fourth age group among parent of ASD was 50 to 59 years old with $3.2 \%(n=4)$. The races of respondent grouped into four groups. They were Malay, Chinese, Indian and other. The percentage of races who participated in this study was 89 Malay, 24 Chinese, 8 Indian and three others. The highest percentage of respondent was Malay with $71.8 \%$, the second highest respondent was Chinese with $19.4 \%$, the third races group was Indian with $6.5 \%$, and other races are $2.4 \%$ only. The mean for races was 1.40 and SD was 0.72 .

\subsection{Descriptive statistic of type of occupation among parent of ASD during prenatal and postnatal}

The categories of occupations into eleven groups included not working, professional, administrative, scientific or artistic, facilitative or assistive, technical or mechanical, nature or recreation, clerical or secretarial, sales or service and operatives. From figure 1 , the highest percentage of a type of occupation during prenatal stage was professionals with $29.8 \%(n=37)$. Technical or mechanical field recorded as the second highest occupation with $21.8 \%(n=27)$. The third highest parent occupation during prenatal stage was administrative with $12.9 \%(n=16)$. The fourth parent occupation during prenatal stage was sales or service with $10.5 \%(n=13)$. Others parental occupation included clerical and secretarial job with $7.3 \%(n=9)$, creative and artistic was $5.6 \%(n=7)$, operatives was $4.0 \%$ $(n=5)$, scientific or analytical was $3.2 \%(n=4)$, facilitation or assistive was $1.6 \%(n=2)$, nature or recreation was $0.8 \%$ $(n=1)$. A parent who was not working is 3 with the percentage were 2.4 .

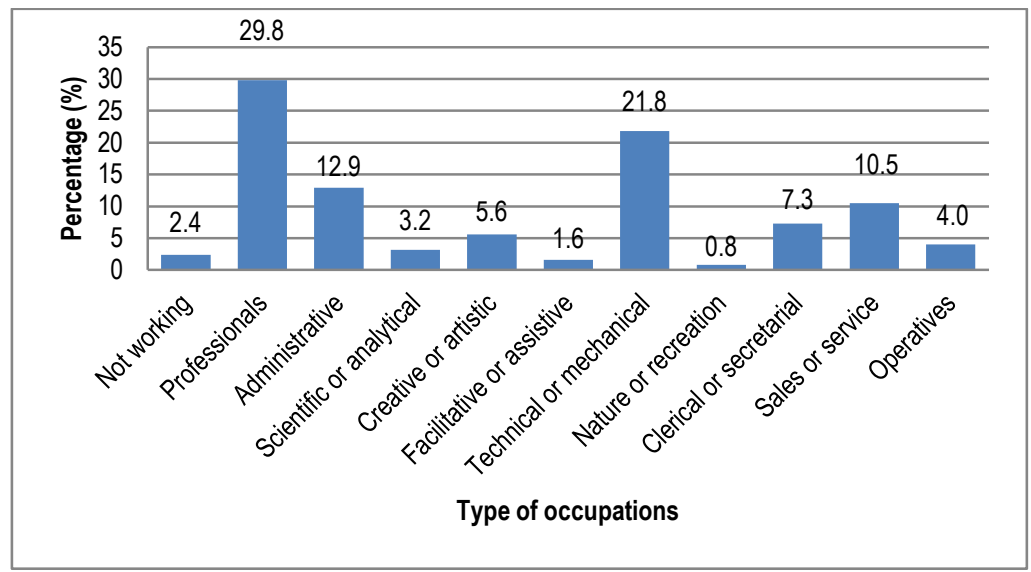

Fig.1.Type of occupation during prenatal stage. 


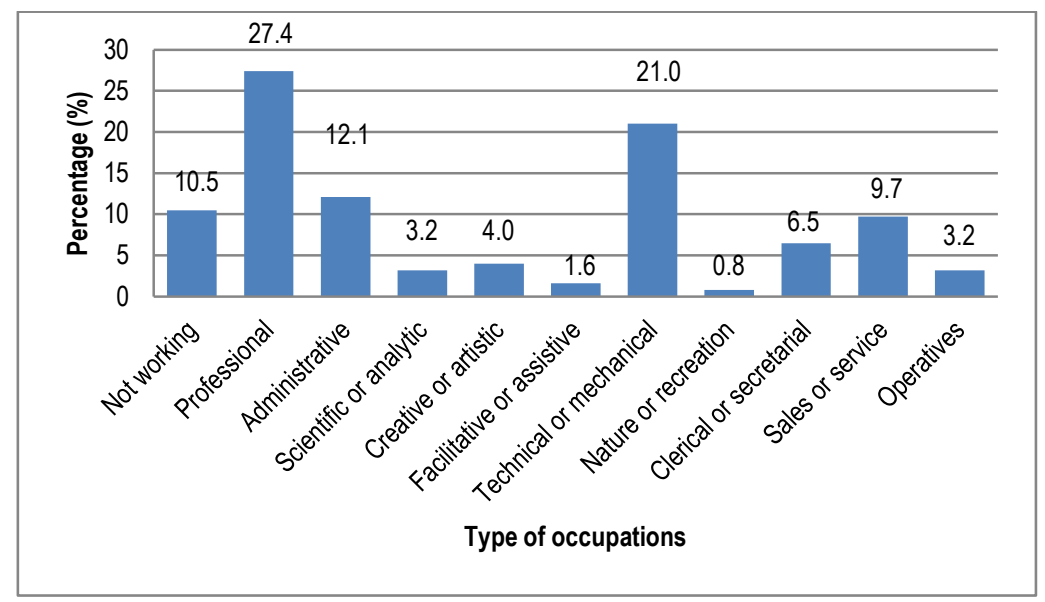

Fig. 2. Type of occupation during postnatal stage.

Based on Fig 2, the highest percentage of the type of occupation during postnatal stage remained in the professional field with $27.4 \%(n=34)$, technical or mechanical with $21.0 \%(n=26)$ and administrative with $12.1 \%$ $(n=15)$. Others parental occupation included sales and services with $9.7 \%(n=12)$, clerical and secretarial is $6.5 \%$ $(n=8)$, creative and artistic was $4.0 \%(n=5)$, operatives was $3.2 \%(n=4)$, scientific or analytical was $3.2 \%(n=4)$, facilitation or assistive was $1.6 \%(n=2)$, nature or recreation was $0.8 \%(n=1)$. However, there is the slight increase in the percentage of the parent not working with $10.5 \%(n=10)$ as compare to $2.4 \%$ during prenatal stage.

\subsection{Descriptive statistic of duration of working, working hours and rest time during working among ASD}

Table 2 indicates the length of working among respondent grouped into six groups. They were 0 to 1 years, 2 to 3 years, 4 to 5 years, 6 to 7 years, 8 to 9 years, and more than ten years. Based on Table 2, most of the parents of ASD have experience with more than ten years of working period with $59.7 \%(n=74 \%)$ and parents who work about 8 to 9 years is $23.4 \%(n=29)$. Parents who work for 6 to 7 years $4.8 \%(n=6)$, parents who have worked for 4 to 5 years is $8.1 \%(n=10)$ and parents who work for 2 to 3 years $1.6 \%(n=2)$. The mean was 7.59 , and the standard deviation was 3.09. The working hours per day among respondents grouped into five groups. They were 2 hours, 4 hours, 6 hours, 8 hours and more than 10 hours. $57.3 \%(n=71)$ parents who are working 8 hours per day and $33.1 \%$ $(n=41)$ parents who work more than10 hours per day. Parents who work 6 hours per day was $1.6 \%(n=2), 4$ hours per day was $5.6 \%(n=7)$ and 2 hours per day was $2.4 \%(n=3)$. The mean was 8.21 , and the standard deviation was 1.96. The relaxing time during working hours among respondents grouped into four groups which included 0 minutes, 30 minutes, 60 minutes or 1 hour and 90 minutes or 1 hour and a half. Most of the parents have 1 hour resting during working hour with $79.0 \%(n=98), 13.7 \%(n=17)$ parent have 30 minutes resting time, only $4.8 \%(n=6)$ parent have 90 minutes resting time and $2.4 \%(n=3)$ having no rest. The mean was 55.40 , and the standard deviation was 14.51. 
Table.2. Duration of working, working hours and rest time during working

\begin{tabular}{lllll}
\hline Variables & Categories & $\begin{array}{l}\text { Frequencies } \\
(\mathrm{n}=124)\end{array}$ & $\begin{array}{l}\text { Percent } \\
\%\end{array}$ & Mean (SD) \\
\hline Duration of working (years) & $0-1$ & 3 & 2.4 & \\
& $2-3$ & 2 & 1.6 & \\
& $4-5$ & 10 & 8.1 & 7.59 \\
& $6-7$ & 6 & 4.8 & $(3.09)$ \\
& $8-9$ & 29 & 23.4 & \\
Working hours per day & $>10$ & 74 & 59.7 & \\
(hours) & 2 & 3 & 2.4 & \\
& 4 & 7 & 5.6 & 8.21 \\
& 6 & 2 & 1.6 & $(1.96)$ \\
Rest time during working hours & 8 & 71 & 57.3 & \\
(Minutes) & $>10$ & 41 & 33.1 & \\
& 0 & 3 & 2.4 & \\
& 30 & 17 & 13.7 & 55.40 \\
& 60 & 98 & 79.0 & $(14.51)$ \\
& 80 & 6 & 4.8 & \\
\hline
\end{tabular}

\subsection{Descriptive statistic of factors that desire parent of ASD to work}

From Fig 3, about 79 parents strongly agreed with the statement for earn more money with $63.7 \%$. The mean was 4.37 with standard deviation was 1.07. The second highest percentage for strongly agree was knowledge development with $36.3 \%(n=45)$. The mean was 3.81 and standard deviation 1.26 . About 44 parents strongly agreed for satisfying an essential need of life with the percentage was $35.5 \%$. The mean was 3.94 , and the standard deviation was 1.11. Other factors which contribute desire parent to work are own interest with $34.7 \%(n=43)$, for personal commitment was $33.9 \%(n=42)$, be productive and useful to the society was $30.6 \%(n=38)$, pride and proud was $25.0 \%(n=31)$, ambitious was $16.9 \%(n=21)$, for pleasure and motivated from others were both $8.9 \%$ $(n=11)$, for safety and secure was $6.5 \%(n=8)$, to get respect from society $5.6 \%(n=7)$, people need to talk to me was $4.8(n=6)$, just for time pass was $4.0(n=5)$, due to empathy and no other options were both $3.2 \%(n=4)$ and lastly is compulsion from others was $0.8 \%$ with $(n=1)$.

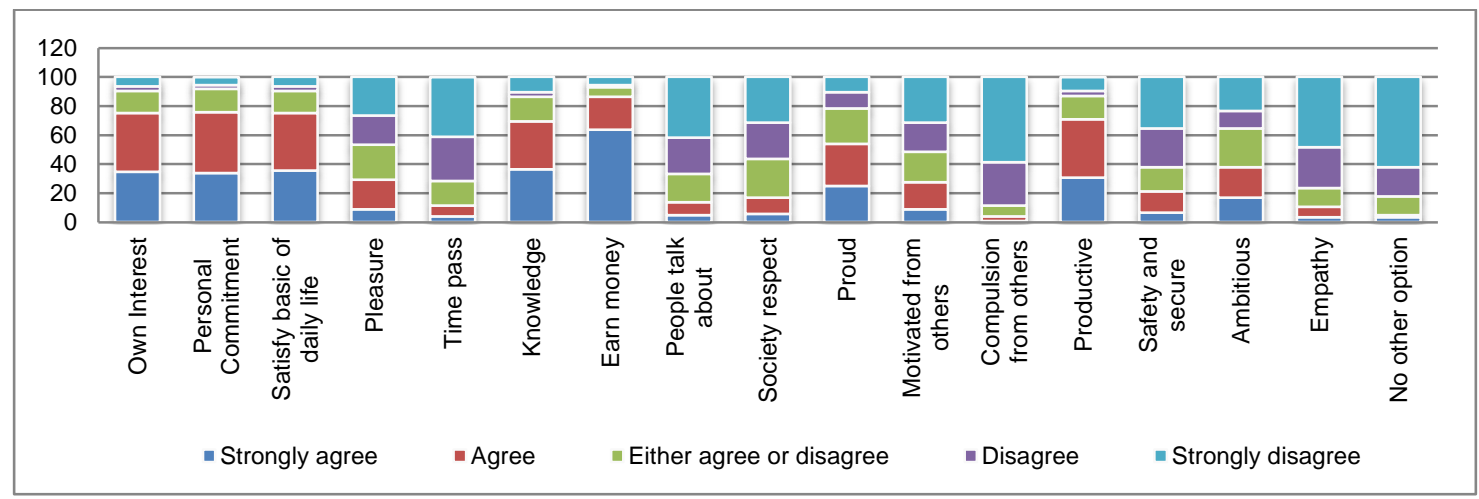

Fig.3.Factors that desire parent of ASD to work 


\section{Discussion}

Finding of this study showed in Figure 1 and 2 there was a slight increase in the percentage of parents not working during postnatal as compared to the prenatal period. Most of the mother were quitting the previous job due to workload, tight schedule and suffer from prenatal stress. Early study mentioned that the causes of prenatal maternal stress (PNMS) among pregnant women are they being exposure to independent life events, a death of husband and invasions by foreign forces. Thus, this will increase the chances of their children having autism, depression and schizophrenia (As cited by Walder, Laplanteb, Sousa-Pires, Veru, Brunet and King, 2014) A study conducted by Kinney, Munir, Crowley and Miller (2008) found that prenatal stress has the association with the development of ASD which increases the risk of having children with ASD. A similar study conducted by Hao, Xue, Yan Ki, and Schepper (2012) to investigate the association between prenatal stress and ASD using Chinese population. The result shows a positive correlation between stress levels of the respondents during prenatal stage with a risk of ASD. Rai, Golding, Magnusson, Steer, Lewis and Dalman (2012) investigated the relationship between exposure to stressful life events during pregnancy was associate with the risk factor of ASD in Sweden and England. However, the result of this study was no proof to support exposure to stressful life events during prenatal stage was relating to higher chances of getting children with ASD.

The current study found that most of the parents of ASD worked as professionals, technical or mechanical during the prenatal and postnatal stage. Parents who work in the professional field are doctors, nurses, pharmacist, teachers, lecturer, lawyer, army, and police officer. Meanwhile, parents who are working in technical and mechanical field work as an engineer, technicians, information technology (IT) programme, and architect. The professional and technical or mechanical job parents might be one of the high risks of delivering the children with ASD. Particularly these jobs are more related to the stereotypical manner of works, especially in thinking and take performance. Early study also investigates the association between ASD and difference type of profession. Based on the result, engineering remains the highest percentage with $24.3 \%$ to be associated with ASD after they compare with others professionals (Wheelwright and Baron-Cohen, 2001). A study conducted by Spek and Velderman (2013) investigated the association between autism and technical professions. This study compared 3 groups which include Autism, Schizophrenia, and Neurotypical. A result of the study showed that Autism group more attachment in technical skills rather than other groups. Besides that, they also found out that the high level of technical skills is linking to impairments in social skills among ASD. According to a study conducted by Auyeung, Baron-Cohen, Ashwin, Knickmeyer, Taylor and Hackett (2009) identified excessive exposure to the testosterone levels significance to the systemizing in children with ASD. They identified with boys rather than girls. The characteristics of the work, in particular, type of occupation such as engineer and scientist were required a lot of systemizing and technical part. This systemizing is relating to the characteristic of the children with ASD. Most of the children were show more interested in playing with technical and mechanical toys such as computer games, Lego and toy vehicles (BaronCohen, 2012). He also stated that most of the workers in high-tech professions usually required more analytical thinking, systemizing and less social interaction with other. However, there is no study found that investigate the association between parental occupation with the communication and social skill deficit among autism spectrum disorder children.

The finding of this study (Figure 3) shows that earn more money, knowledge development and satisfy the basic needs have got the highest percentage for a desire for the parents who works in high- professional area. These desire factors of a parental occupation gene might contribute towards problems in children with ASD.

\subsection{Limitations}

This study had few limitations during data collection. Firstly, the probability of parents to lie or just tick without understanding while answering the self-report questionnaire. Secondly, some of the parents preferred to interview rather than they self-administered. Because this $\mathrm{POQ}$ form has many questions and some of the questions in postnatal part repeated from the prenatal. Thirdly, the analysis of this study was done by descriptive statistic only. No other statistical measures were suitable to use. Therefore, this study only reported the frequency, percentage, 
mean and standard deviation. No other statistical measures used. Finally, this study not used the other standardized parental occupation assessment scales.

\section{Conclusion}

The parent who works in the noble or high professions and technical or mechanical has the high risk of ASD. The factors which contribute to the desired parent to work on those filed are to earn more money, knowledge development and to satisfy basic needs. These desire factors of a parental occupation might contribute towards problems in children with ASD. Therefore, future research need to examine how earn more money, knowledge development and to satisfy basic needs could help towards communication and social deficits in autistic children. Future research could also examine one particular occupation such as engineer or professional and to identify the pattern of works and their working environment that affects the ASD. Additionally, the studies need to examine with larger sample size and with other standardized occupational scales. Furthermore, to investigate which stereotypical occupation and gene that may affects the social and communication skills in ASD.

\section{Acknowledgements}

This present study supported by Research Management Institution of Universiti Teknologi MARA (UiTM) and funded by Fundamental Research Grant Scheme (FRGS) 600-RMI/FRGS 5/3 (27/2014), Ministry of Higher Education (MOHE), Malaysia.

\section{References}

Autism and Developmental Disabilities Monitoring Network Surveillance Year 2010 Principal Investigators. (2014). Prevalence of Autism Spectrum Disorder Among Children Aged 8 Years - Autism and Developmental Disabilities Monitoring Network, 11 Sites, United States, 2010. Retrieved from http://www.cdc.gov/mmwr/pdf/ss/ss6302.pdf.

Auyeung, B., Baron-Cohen, S., Ashwin, E., Knickmeyer, R., Taylor, K., \& Hackett, G. (2009). Fetal testosterone and autistic traits. British Journal of Psychology, 100, 1-22.

Azizan, H. (2008, April 27). The burden of autism. The Star Online. Retrieved from http://www.thestar.com.my/Story/?file=\%2F2008\%2F4\%2F27\%2Ffocus $\% 2 F 21080181 \&$ sec=focus.

Baron-Cohen, S., Wheelwright, S., Stott, C., Bolton, P., \& Goodyer, I. (1997). Is There a Link between Engineering and Autism? Autism, 1(1), 101-109.

Baron-Cohen, S., Bolton, P., Wheelwright, S., Scahill, V., Short, L., Mead, G., \& Smith, A. (1998). Autism occurs more often in families of physicists, engineers, and mathematicians. Autism, 2, 296-301.

Baron-Cohen, S. (2012, November). Autism and the technical mind. Retrieved August 14, 2014, from http://docs.autismresearchcentre.com/papers/2012_BC\%202012_SciAm.pdf.

Buchen L. (2011). Scientists and autism: When geeks meet. Nature. 479(7371), 25-27.

Department of Statistic Malaysia. (2010). Demographic indicators. Retrieved on November 2, 2014, http://www.kpwkm.gov.my/BM/Upload/BAB\%201\%20PENDUDUK_bm.pdf.

Diament, M. (2014, May 20). Parent's Line of Work May Increase Autism Risk - Disability Scoop. Retrieved August 14, 2014, from http://www.disabilityscoop.com/2014/05/20/parents-work-autism/19380/. 
Dickerson, A. S., Pearson, D. A., Loveland, K. A., Rahbar, M. H., \& Filipek, P. A. (2014). Role of parental occupation in autism spectrum disorder diagnosis and severity. Autism Spectrum Disorders, 8, 997-1007.

Griffin, R., \& Westbury, C. (2011). Infant EEG activity as a biomarker for autism: a promising approach or a false promise? BMC Medicine, 9(61).

Guney, E., \& Iseri, E. (2013). Genetic and environmental factors in autism. Recent Advances in Autism Spectrum Disorders, 1, 321-329.

Jarrold, C., \& Routh, D. A. (1998). Is there really a link between engineering and autism? A reply to Baron-Cohen et al. Autism, 2, 281 - 289.

Jayachandran. V, Mohd, F.M.Z., \& Smily, J.P.V (2015). The relationship between visual perception and imitation in school function in autism, Procedia - Social and Behavioral Sciences. 202, 67-75.

Hao, Xue, Yan Ki, and Schepper (2012). A Preliminary Investigation of Prenatal Stress and Risk Factors of Autism Spectrum Disorder. Autism Insights. 4, 15-30.

Kalkbrenner, A. E., Schmidt, R. J., \& Penlesky, A. C. (2014). Environmental chemical exposures and autism spectrum disorders: a review of the epidemiological evidence. Curr Probl Pediatr Adolesc Health Care, 277-318.

Kinney, D. K., Munir, K. M., Crowley, D. J., \& Miller, A. M. (2008). Prenatal stress and risk for autism. Neuroscience and Biobehavioral Reviews, 32(8), 1519-1532.

Nurul'ain S, Smily, J.P.V., Jayachandran. V, Ruwinah, A.K., \& Dewi-alliana, R (2015). Effect of occupational performance visuo-auditory imitation intervention on visual perception among children with autism: pilot study, Research Journal of Recent Sciences, 4 (12),1-6.

Rai, D., Golding, J., Magnusson, C., Steer, C., Lewis, G., \& Dalman, C. (2012). Prenatal and early life exposure to stressful life events and risk of autism spectrum disorders: population-based studies in sweden and england. Plos One, 7(6), 1-8.

Senju A. (2013) Atypical development of spontaneous social cognition in autism spectrum disorders. Brain Dev. 35, 96-101.

Smily, J.P.V., Noor-Asyikin A., \& Jayachandran. V. (2016). Emotional Behaviour among Autism and Typically Developing Children in Malaysia, Procedia - Social and Behavioral Sciences, in press.

Smily, J.P.V., Ruwinah, A.K., \& Jayachandran, V (2015), Evaluation of Occupational Performance Imitation Approach (OPIA) on three Imitative Learning among Autism Spectrum Disorder, case series, Procedia - Social and Behavioral Sciences, 202, 56-58.

Spek, A. A., \& Velderman, E. (2013). Examining the relationship between autism spectrum disorders and technical professions in high functioning adults. Research in Autism Spectrum Disorders, 7(5), 606-612.

Walder, D. J., Laplanteb, D. P., Sousa-Pires, A., Veru, F., Brunet, A., \& King, S. (2014). Prenatal maternal stress predicts autism traits in 61/2 year-old children: project ice storm. Psychiatry Research, 219(2), 353-360.

Wheelwright, S., \& Baron-Cohen, S. (2001). The Link Between Autism and Skills such as Engineering, Maths, Physics and ComputingA Reply to Jarrold and Routh, Autism,1998,2 (3):281-9. Autism, 5, 223-227. 